\title{
Rancangan Kebutuhan Rak Dan Luas Ruangan Penyimpanan Rekam Medis Di Rumah Sakit Putri Hijau
}

\author{
${ }^{1}$ Welly Satria Dewi, ${ }^{2}$ Siti Muthmainnah \\ Program Studi D-III Perekam Medis dan Informasi Kesehatan, Universitas Imelda Medan
}

\begin{tabular}{l}
\hline Article Info \\
\hline Article history: \\
Received Feb14, 2020 \\
Revised Feb 25, 2020 \\
Accepted Feb28, 2020
\end{tabular}

\section{Keywords:}

Medical Records Storage Shelves Room Area

\begin{abstract}
ABSTRAK
Medical records are stored in a storage room to make it easier to retrieve and return medical record files. Increased patient visits result in increased thickness and addition of new medical records, so that the shelves become full resulting in the process of storage and return to be hampered and cause physical damage to the medical record file. Then the researchers aimed to determine the need for shelves and spacious medical record storage room at Putri Hijau Hospital. This research uses descriptive quantitative method that is by describing the results of the research as it is and comparing with the theory then conclusions are drawn. The subjects in this study were the medical record file storage space, the object in this study was the medical record file and storage rack. The results of this study indicate that the number of medical record file storage shelves at the Putri Hijau Hospital is 20 rack with room area of $100 \mathrm{~m}^{2}$. There are 15 shelves with a room area of $75 \mathrm{~m}^{2}$ in an active room and 5 shelves with a room area of $25 \mathrm{~m}^{2}$ in an inclusive room. With an active room area that is available to accommodate the need for additional active medical record shelves as much as 2 units, so that adequate storage of medical record shelves can facilitate officers in storing and returning patient medical record files and maintaining confidentiality and avoiding physical damage to medical record documents.
\end{abstract}

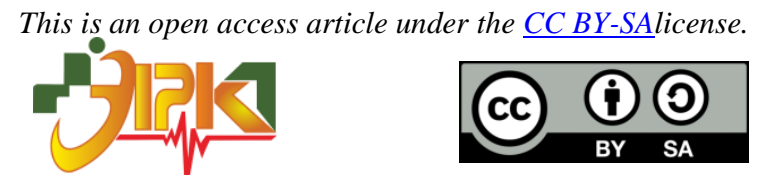

\section{Corresponding Author:}

Welly Satria Dewi,

Program Studi D-III Perekam Medis dan Informasi Kesehatan,

Universitas Imelda Medan,

Jl. Bilal No. 52 Kelurahan Pulo Brayan Darat I Kecamatan Medan Timur, Medan - Sumatera Utara.

Email: bundadzakiya@gmail.com

\section{PENDAHULUAN}

Rumah sakit adalah institusi pelayanan kesehatan yang menyelenggarakan pelayanan kesehatan perorangan secara paripurna yang menyediakan pelayanan rawat inap, rawat jalan, dan gawat darurat (UU No.44 tahun 2009). Rekam Medis adalah berkas atau bukti tertulis yang berisikan catatan dokumen tentang identitas pasien, pemeriksaan, pengobatan, tindakan dan pelayanan lain kepada pasien pada sarana pelayanan kesehatan yang sewaktu- waktu dapat dipertanggung jawabkan (Permenkes RI No.269/MENKES/III tahun 2008).

Setiap sarana pelayanan kesehatan diwajibkan menyelenggarakan rekam medis, salah satu manfaatnya sebagai bukti pelayanan kesehatan yang dilakukan dirumah sakit. Dalam Undang-undang No.29 tahun 2004 tentang praktik kedokteran pasal 46 ayat (1) menegaskan 
bahwa dokter dan dokter gigi wajib membuat rekam medis dalam menjalankan praktik kedokteran. Rekam medis yang telah diisi lengkap oleh pemberi pelayanan kesehatan selanjutnya akan diolah menjadi laporan kemudian akan disimpan keruang penyimpanan. Penyimpanan merupakan kegiatan menyimpan, penataan atau penyimpanan (storage) berkas rekam medis untuk mempermudah pengambilan kembali (retrieval) (Erydan Warih, 2011).

Rekam medis disimpan dalam rak penyimpanan agar terjaga kerahasiaannya, terhindar dari kerusakan dan mempermudah petugas dalam pengambilan dan pengembalian rekam medis. Agar pelayanan menjadi efektif dan efesien, selain memerlukan rak penyimpanan yang cukup, juga perluruangan penyimpanan yang bisa memuat rak penyimpanan tersebut agar dapat menyimpan rekam medis pasien dalam jangka waktu tertentu guna pemeriksaan di waktu yang akan datang dan memudahkan pengembalian kembali oleh petugas.

Berdasarkan hasil penelitian (Anggy, dkk, 2014) ruangan penyimpanan di RSUD dr.Soekardjo Kota Tasikmalaya memiliki tata ruang yang kurang efektif. Ruangan penyimpanan rawat jalan memiliki 10 rak penyimpanan dokumen rekam medis. Ukuran panjang rak semua sama akan tetapi sebelumnya petugas rekam medis pernah menambahkan 2 rak baru yang disimpan disatukan berdampingan sehingga tata ruang yang ada menjadi semakin sempit. Ukuran panjang rak di RSUD dr. Soekardjo Kota Tasikmalaya berbedabeda, 2 rak yang memiliki ukuran $279,5 \mathrm{~cm}$ dan 8 rak memiliki $179,5 \mathrm{~cm}$. Jarak antar rak berbeda-beda sehingga dilakukan perhitungan hasil rata-rata untuk mempermudah perbandingan kesesuaian tata ruang. Ukuran rak tempat penyimpanan dokumen rekam medis berdasarkan hasil pengukuran ialah tinggi rak $180 \mathrm{~cm}$; panjang rak $229,5 \mathrm{~cm}$; lebar rak $50 \mathrm{~cm}$; rata-rata jarak antar rak yaitu $63 \mathrm{~cm}$; dan luas ruangan $32,06 \mathrm{~m}^{2}$.

Ukuran perbaikan tata ruang untuk penyimpanan RSUD dr.Soekardjo Kota Tasikmalaya ialah untuk tinggi rak penambahan ukuran $5,5 \mathrm{~cm}$, panjang rak ada pengurangan ukuran yaitu $87 \mathrm{~cm}$, lebar rak penambahan ukuran $4 \mathrm{~cm}$, jarak antar rak penambahan ukuran $39 \mathrm{~cm}$, luas ruangan sebelumnya $32,06 \mathrm{~m}^{2}$ diperbaiki kebutuhan ukuran ruangan menjadi $35,69 \mathrm{~m}^{2}$.

Berdasarkan hasil perhitungan dari (Lubis \& Handayani, 2018) dapat diketahui bahwa jumlah rak yang tersedia di RSU IPI Medan masih kekurangan rak untuk penyimpanan berkas rekam medis baik rawat inap maupun rawat jalan. Jumlah rata-rata rekam medis baru pada tahun 2016 rawat inap sebanyak 54.000 dan rawat jalan 63.000 berkas rekam medis. Ukuran rata-rata ketebalan dari berkas rekam medis untuk rawat inap panjang $32 \mathrm{~cm}$, lebar $25 \mathrm{~cm}$, dan ketebalan $0,5 \mathrm{~cm}$ untuk rawat jalan panjang $32 \mathrm{~cm}$, lebar $25 \mathrm{~cm}$ dan ketebalan $1,5 \mathrm{~cm}$.

Berdasarkan studi pendahuluan yang telah dilakukan di Rumah Sakit Putri Hijau, diperoleh informasi bahwa Rumah Sakit Putri Hijau menggunakan sistem penyimpanan sentralisasi, dan sistem penjajaran terminal digit filing system, jenis rak yang digunakan adalah rak besi terbuka. Jumlah rak penyimpanan yaitu 20 rak, disetiap satu rak penyimpanan terdapat 21 subrak, jumlah total subraknya 420 rak dengan ukuran 100x40cm. Pada ruang penyimpanan di Rumah Sakit Putri Hijau terbagi menjadi 4 ruangan penyimpanan berkas rekam medis, terdiri dari 3 ruangan untuk berkas rekam medis aktif dan 1 ruangan untuk berkas rekam medis inaktif, pada setiap ruangan memiliki 5 rak penyimpanan.

Berkas rekam medis yang ada di rak penyimpanan sangatlah padat, dapat menimbulkan kerusakan fisik dokumen rekam medis pasien yang akan berdampak pada isi rekam medisnya dan dengan terbaginya ruangan penyimpanan menjadi 4 ruangan akan membuat petugas kesulitan dalam pengambilan berkas rekam medis sehingga pendistribusian ke klinik menjadi terlambat. Maka dari itu perlu direncanakan kebutuhan rak dan luas ruangan agar berkas rekam medis terjaga dari kerusakan dan mempermudah proses pengambilan dan pendistribusian rekam medis. Berdasarkan penjelasan tersebut, peneliti tertarik untuk 
mengambil judul "Rancangan Kebutuhan Rak dan Luas Ruangan Penyimpanan Rekam Medis di Rumah Sakit Putri Hijau".

\section{METODE PENELITIAN}

A. Jenis Penelitian

Jenis penelitian yang digunakan adalah penelitian deskriptif kuantitatif, yaitu penelitian yang dilakukan untuk mendeskripsikan atau menggambarkan suatu keadaan secara objektif. Metode penelitian deskriptif digunakan untuk membuat penilaian terhadap suatu kondisi untuk memecahkan atau menjawab permasalahan yang sedang dihadapi pada suatu sekarang dan menganalisis masalah tersebutapa adanya (Notoadmojo, 2012). Waktu penelitian ini dilaksanakan mulai dari bulan Februari-April 2019. Tempat penelitian dilaksanakan dibagian ruang penyimpanan rekam medis di Rumah Sakit Putri Hijau Jl. Putri Hijau No. 17 Medan.

B. Subyek dan Obyek Penelitian

Subjek dalam penelitian ini adalah ruang penyimpanan berkas rekam medis di Rumah Sakit Putri Hijau. Objek dalam penelitian ini adalah berkas rekam medis dan rak penyimpanan rekam medis di Rumah Sakit Putri Hijau.

C. Variabel Penelitian

Variabel adalah ukuran atau ciri yang dimiliki oleh anggota kelompok yang berbeda dengan yang dimiliki oleh kelompok lain yang digunakan sebagaiciri, sifat, atau ukuran yang dimiliki atau didapat oleh kesatuan penelitian (Notoadmojo, 2012). Adapun variabel-variabel yang akan diamati oleh peneliti adalah sebagai berikut:

1. Luas ruangan

2. Rata-rata kunjungan pasien

3. Jumlah rak penyimpanan

4. Ukuran rak penyimpanan

5. Ketebalan berkas rekam medis

D. Definisi operasional

Definisi operasional adalah seperangkat petunjuk yang lengkap tentang apa yang harus diamati oleh peneliti dan bagaimana mengukur variabel atau konsep (Haddy, 2017).

1. Luas ruangan adalah ukuran ruangan penyimpanan rekam medis yang dihitung dengan menggunakan rumus matematika.

2. Rata-rata kunjungan pasien adalah jumlah pasien yang berobat ke rumah sakit.

3. Jumlah rak penyimpanan adalah jumlah rak yang tersedia untuk menampung berkas rekam medis pasien.

4. Ukuran rak penyimpanan adalah ukuran rak penyimpanan berkas rekam medis dihitung menggunakan rumus matematika.

5. Ketebatalan berkas rekam medis adalah ukuran tebal berkas rekam medis yang diambil rata-rata ketebalannya dihitung menggunakan rumus matematika.

E. Instrumen Penelitian

Instrumen penelitian adalah alat yang digunakan untuk pengumpulan data (Notoadmojo, 2012). Maka instrumen yang digunakan dalam penelitian di Rumah Sakit Putri Hijau adalah:

1. Pengamatan (Observation)

Pengamatan (observation) yaitu proses pencatatan pola perilaku subjek, objek, atau kejadian yang sistematik tanpa adanya komunikasi dengan individuindividu yang diteliti (Haddy, 2017).

2. Wawancara (Interview)

Wawancara (interview) yaitu metode pengumpulan data dengan menggunakan pertanyaan secara lisan kepada subjek penelitian (Haddy, 2017). 
F. Cara Pengumpulan Data

Cara pengumpulan data pada penelitian ini menggunakan cara pengumpulan data primer. Yang dimaksud dengan data primer adalah data yang diperoleh secara langsung dari sumbernya (tidak melalui media perantara) atau dengan kata lain data yang diperoleh dengan survei lapangan yang menggunakan semua metode pengumpulan data original (Haddy, 2012).

G. Teknik Pengolahan Data

Data yang telah terisi dan terkumpul dijadikan informasi yang dapat digunakan untuk menjawab tujuan penelitian (Notoadmojo, 2012). Teknik pengolahan data yang dilakukan yaitu:

1. Editing

Editing yaitu kegiatan yang dilakukan untuk meninjau atau mengoreksi kembali hasil data observasi yang telah dikumpulkan guna untuk mengetahui kesalahankesalahan.

2. Tabulating

Tabulating yaitu menata kembali data yang telah diperoleh berdasarkan variabel yang diteliti guna memudahkan analisis data, dimana setiap pernyataan yang sudah diberi kode dikelompokkan lalu dihitung dan menjumlahkan kemudian dituliskan dalam bentuk tabel.

3. Penyajian Data

Penyajian data yaitu suatu cara pengolahan data dengan menyajikan hasil dari pengumpulan data berupa teks.

H. Analisis Data

Analisis data adalah upaya atau cara untuk mengolah data menjadi informasi sehingga karakteristik data tersebut bisa dipahami dan bermanfaat untuk solusi permasalahan, terutama masalah yang berkaitan dengan penelitian (Haddy, 2017).

\section{HASIL DAN PEMBAHASAN}

\subsection{Hasil}

Berdasarkan penelitian yang dilakukan penulis mengenai "Rancangan Kebutuhan Rak dan Luas Ruang Penyimpanan Berkas Rekam Medis di Rumah Sakit Putri Hijau” adalah perlu adanya penambahan rak penyimpanan berkas rekam medis dan penataan ruangan penyimpanan berkas rekam medis.

\section{Rata-rata Kunjungan Pasien}

Kunjungan pasien baru pertahun dapat dilihat pada tabel berikut:

Tabel 1. Jumlah Kunjungan Pasien Baru Pertahun di Rumah Sakit Putri Hijau

\begin{tabular}{ccc}
\hline No & Tahun Kunjungan & Jumlah Dokumen Rekam Medis \\
\hline 1 & 2014 & 86875 \\
\hline 2 & 2015 & 88990 \\
\hline 3 & 2016 & 89543 \\
\hline 4 & 2017 & 82697 \\
\hline 5 & 2018 & 89998 \\
\hline \multicolumn{3}{c}{ Sumber: Data Primer }
\end{tabular}

Berdasarkan tabel 1 diatas jumlah dokumen rekam medis di Rumah Sakit Putri Hijau adalah 438103 berkas.

\section{Rata-rata Ketebalan Berkas Rekam Medis}


Dari pengukuran 50 berkas rekam medis yang dilakukan peneliti dilapangan, di dapatkan rata-rata ketebalan berkas rekam medis yang diuraikan pada tabel berikut:

Tabel 2. Ketebalan Berkas Rekam Medis No UkuranKetebalan BRM (cm) Banyak Berkas Jumlah Ketebalan

\begin{tabular}{cccc}
\hline 1 & 0,1 & 26 & 2,6 \\
\hline 2 & 0,3 & 9 & 2,7 \\
\hline 3 & 0,5 & 7 & 3,5 \\
\hline 4 & 0,9 & 5 & 4,5 \\
\hline 5 & 1,7 & 3 & 5,1 \\
\hline & Total & $\mathbf{5 0}$ & $\mathbf{1 8 , 4}$ \\
& Rata-rata & & $\mathbf{0 , 3 6 8} \mathbf{~ c m}$
\end{tabular}

Sumber: Data Primer

Berdasarkan tabel 2 diatas rata-rata ketebalan berkas rekam medis di Rumah Sakit Putri Hijau yaitu $0,368 \mathrm{~cm}$.

\section{Ukuran Rak Penyimpanan Berkas Rekam Medis Rumah Sakit Putri Hijau}

Rak penyimpanan berkas medis yang tersedia diruang penyimpanan berkas rekam medis RS Putri Hijau dengan jumlah keseluruhan 20 unit. Adapun ketentuan dari rak tersebut adalah 1 rak terdiri dari 7 baris 3 kolom menjadi 21 subrak setiap 1 rak penyimpanan. Ukuran subrak kesamping yaitu100 $\times 40 \mathrm{~cm}=4000 \mathrm{~cm}$. Dengan ketebalan berkas rekam medis ratarata $0,368 \mathrm{~cm}$, maka diperoleh jumlah berkas rekam medis di dalam satu rak yaitu :

$=3 \times(4000 / 0,368) \times 7$

$=3 \times 10869,5652 \times 7$

$=228260,869 \approx 228261$

Jadi, jumlah berkas rekam medis dalam 1 rak sebanyak 228261 rekam medis.

Jumlah Kebutuhan Rak Penyimpanan Berkas Rekam Medis Rumah Sakit Putri Hijau

Dengan terjawabnya jumlah berkas rekam medis dalam 5 tahun terakhir yaitu 438103 berkas, dan jumlah berkas berkas rekam medis dalam 1 rak adalah 228261 berkas,maka jumlah kebutuhan rak berkas rekam medis di Rumah Sakit Putri Hijau yaitu :

$=438103: 228261$

$=1,919 \approx 2 \mathrm{rak}$

Jadi kebutuhan rak berkas rekam medis di Rumah Sakit Putri Hijau sebanyak 2 rak.

\section{Kebutuhan Luas Ruangan Penyimapanan Berkas Rekam Medis Rumah Sakit Putri Hijau}

Berdasarkan observasi yang telah dilakukan di Rumah Sakit Putri Hijau ruang penyimpanan berkas rekam medis terdapat 4 ruang, terbagi menjadi 3 ruang rekam medis aktif dan 1 ruang rekam medis inaktif. Berdasarkan hasil observasi diketahui bahwa ruang penyimpanan ruang medis selalu memiliki banyak ruang sehingga membuat petugas kesulitan dalam mencari berkas rekam medis. Jarak antara rak 1 dengan yang lain sudah memenuhi nilai ideal yaitu $100 \mathrm{~cm}$. Idealnya lorong untuk rak penyimpanan adalah 80$100 \mathrm{~cm}$ (Rustiyanto, 2011). Berikut adalah denah ruang penyimpanan rekam medis di Rumah Sakit Putri Hijau.

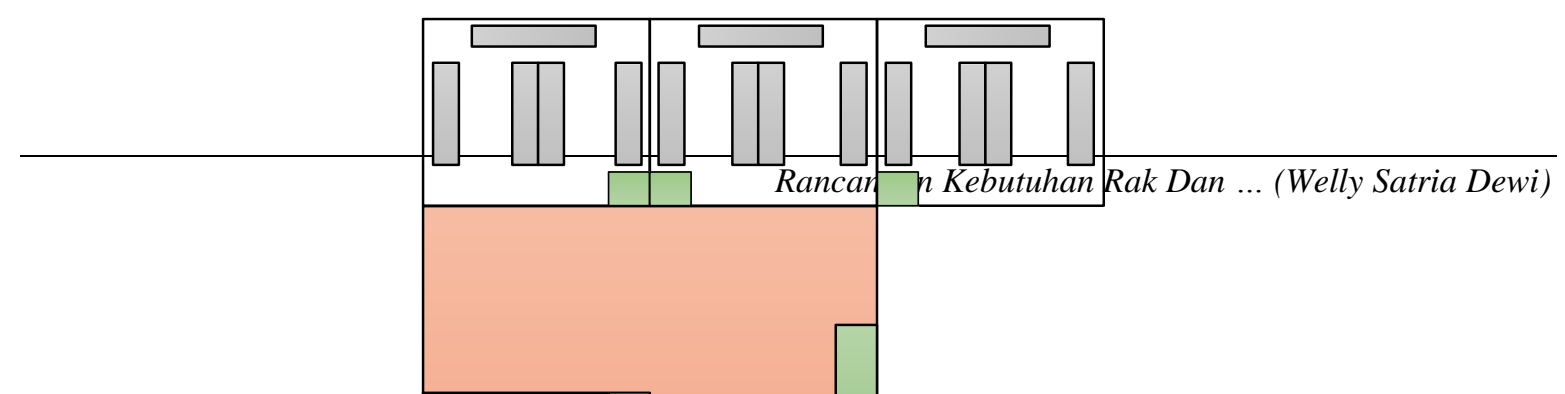




\section{Gambar 1. Denah Ruang Penyimpanan Rekam Medis Di Rumah Sakit Putri Hijau}

Keterangan :

: Rak penyimpanan berkas rekam medis.

: Pintu masuk ruang rekam medis.

: Ruang meja dan kursi petugas rekam medis.

: Ruang penyimpanan berkas rekam medis inaktif

$\square$ : Ruang penyimpanan berkas rekam medis aktif

Berdasarkan observasi diruang penyimpanan rekam medis Rumah Sakit Putri Hijau, ruang penyimpanan memungkinkan untuk penambahan jumlah rak penyimpanan yang hanya 2 rak saja. Terdapat 3 ruangan yang berdekatan, dimana tiap ruangan memiliki ukuran masing-masing $5 \times 5 \mathrm{~m}=25 \mathrm{~m}^{2}$. Jika dinding yang memisahkan antar ruangan dibuka akan diperoleh ukuran luas ruangan $75 \mathrm{~m}^{2}$ akan mempermudah petugas dalam mencari berkas rekam medis pasien.

Dengan luas ruangan $75 \mathrm{~m}^{2}$ tersebut dapat menampung 17 rak berkas rekam medis aktif pasien yang dapat dibuktikan dari perhitungan kebutuhan luas rungan berikut ini:

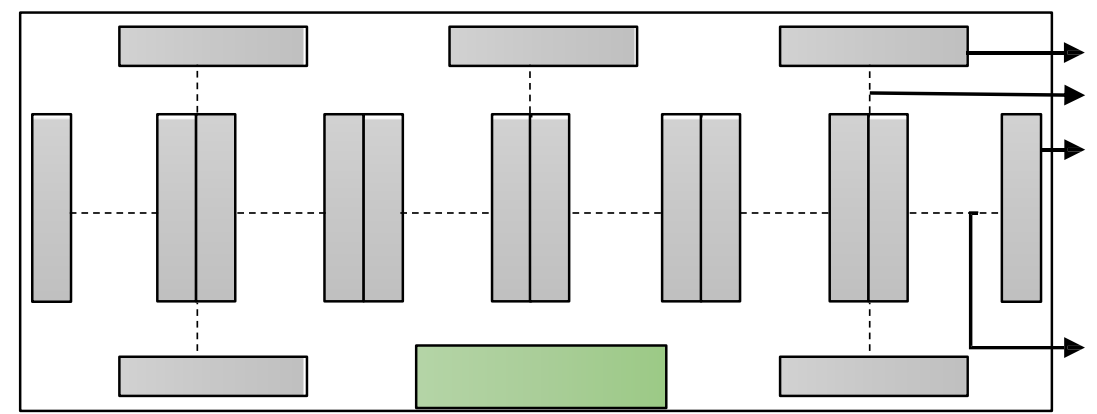

Gambar 2. DenahRuang PenyimpananRekam Medis Aktif

Keterangan :

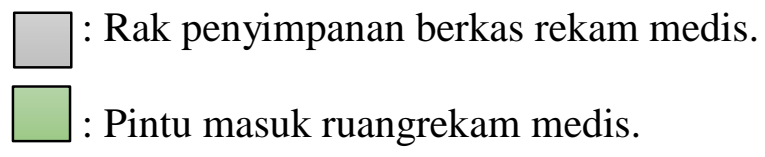

Panjang ruangan $=($ jarak antar rak $\mathrm{x}$ jumlah $)+($ lebar rak $\mathrm{x}$ jumlah $)$

$=(100 \times 6)+(40 \times 6)$

$=600+240$

$=840 \mathrm{~cm}=8,4 \mathrm{~m}$

Lebar ruangan $=($ jarak antar rak $\mathrm{x}$ jumlah $)+($ panjang rak $\mathrm{x}$ jumlah $)$

$=(60 \times 2)+\{(40 \times 2)+(300 \times 1)\}$ 
$=120+380$

$=500 \mathrm{~cm}=5 \mathrm{~m}$

Luasruangan = panjang ruangan $\mathrm{x}$ lebar ruangan

$=8,4 \times 5$

$=42 \mathrm{~m}^{2}$

Jadi, luas ruangan yang dibutuhkan untuk menyimpan 17 rak berkas rekam medis aktif yaitu $42 \mathrm{~m}^{2}$, luas ruang yang tersedia yaitu $75 \mathrm{~m}^{2}$. Maka dari itu Rumah Sakit Putri Hijau tidak perlu menambah luas ruangan penyimpanan berkas rekam medis.

\subsection{Pembahasan}

\section{Rata-rata Kunjungan Pasien}

Setiap harinya pasien terus bertambah dan berkas rekam medisnya bertambah pula seiring dengan bertambahnya jumlah pasien setiap hari dan ketebalan berkas rekam medis didalam rak penyimpanan akan bertambah pula. Berdasarkan hasil penelitian yang penulis lakukan di Rumah Sakit Putri Hijau bahwa rata-rata kunjungan pasien mulai dari tahun 20142018 yaitu berjumlah 438103 orang. Dengan jumlah kunjungan pasien sebanyak 438103, sesuai dengan bertambahnya jumlah pasien baru setiap harinya, maka jumlah dan ketebalan berkas rekam medis akan bertambah pula sehingga akan berpengaruh kepada kebutuhan rak penyimpanan berkas rekam medis.

\section{Rata-rata Ketebalan Berkas Rekam Medis}

Ketebalan berkas rekam medis akan terus bertambah setiap harinya seiring dengan bertambahnya pasien yang berobat kerumah sakit. Semakin banyak pasien baru yang datang berobat kerumah sakit maka semakin bertambah pula jumlah rekam medis didalam rak. Sesuai dengan hasil penelitian di Rumah Sakit Putri Hijau, ukuran ketebalan berkas rekam medis yang berjumlah 50 berkas adalah $18,4 \mathrm{~cm}$ dengan rata-rata ukuran untuk satu berkas rekam medis adalah $0,368 \mathrm{~cm}$.

\section{Ukuran Rak Penyimpanan Berkas Rekam Medis Rumah Sakit Putri Hijau}

Di Rumah Sakit Putri Hijau terdapat 20 unit rak penyimpanan dengan ukuran rak yang sama. Adapun ketentuan dari rak tersebut adalah 1 rak terdiri dari 7 baris 3 kolom menjadi 21 sub rak. Ukuran sub rak ke samping yaitu $4000 \mathrm{~cm}$. Dengan ketebalan berkas rekam medis rata-rata $0,368 \mathrm{~cm}$, maka diperoleh jumlah berkas rekam medis di dalam 1 rak yaitu 228261 berkas rekam medis. Dengan jumlah tersebut, jika dilihat dari jumlah berkas rekam medis dalam 5tahun terakhir sebanyak 438103 berkas maka bisa diprediksi bahwa jumlah rak masih kurang.

\section{Jumlah Kebutuhan Rak Penyimpanan Berkas Rekam Medis Rumah Sakit Putri Hijau}

Berdasarkan perhitungan prediksi kebutuhan rak penyimpanan berkas rekam medis saat ini adalah 22 unit rak. Jika saat ini memiliki 20 rak, maka rumah sakit perlu menambah 2 rak lagi agar kebutuhan rak dapat tercukupi dan dapat menampung semua berkas rekam medis pasien secara sistematis dan tidak menyulitkan petugas dalam pencarian berkas rekam medis pasien. Penambahan rak juga hendaknya disesuaikan dengan luas ruangan penyimpanan agar rak yang di butuhkan dapat tertata dengan rapi.

\section{Kebutuhan Luas Ruangan Penyimpanan Berkas Rekam Medis Rumah Sakit Putri Hijau}


Ruang penyimpanan di Rumah Sakit Putri Hijau yang ada saat ini memungkinkan untuk penambahan jumlah rak penyimpanan yang hanya 2 rak saja, hanya saja desain dan dinding yang memisahkan antar ruangan sebaiknya dibuka agar 3 ruangan dijadikan 1 ruangan dan agar mempermudah petugas dalam mencari dan menyimpan berkas rekam medis pasien. Perhitungan kebutuhan luas ruangan penyimpanan dapat ditentukan setelah diketahui jumlah rak yang dibutuhkan dan menentukan jarak antar rak,untuk menampung 2 rak baru yang jarak antar raknya $100 \mathrm{~cm}$ telah diperhitungkan luasn ya yaitu $42 \mathrm{~m}^{2}$ untuk ruang rekam medis aktif. Sedangkan untuk ruang rekam medis in aktif telah tersedia 1 ruangan yang berukuran $5 \times 5 \mathrm{~m}=25 \mathrm{~m}^{2}$ dengan jumlah rak penyimpanan sebanyak 5 unit rak penyimpanan. Jadi total keseluruhan luas ruangan penyimpanan yang tersedia untuk berkas rekam medis aktif yaitu $75 \mathrm{~m}^{2}$, dengan jumlah rak penyimpanan berkas rekam medis aktif sebanyak 17 unit rak penyimpanan.

\section{KESIMPULAN}

Adapun kesimpulan yang diambil dalam penelitian ini adalah :

1. Jumlah rak penyimpanan berkas rekam medis yang ada di Rumah Sakit Putri Hijau saat ini adalah 20 rak (15 rak aktif dan 5 rak in aktif). Berdasarkan hasil perhitungan rata-rata jumlah kunjungan pasien baru dari tahun 2014-2018 sebanyak 438103, ratarata ketebalan berkas rekam medis yaitu $0,368 \mathrm{~cm}$, dan jumlah berkas rekam medis dalam 1 rak sebanyak 228261 yang dilakukan di rak penyimpanan yang ada di Rumah Sakit Putri Hijau diprediksi rak penyimpanan masih membutuhkan penambahan rak sebanyak 2 rak.

2. Ruang penyimpanan rekam medis di Rumah Sakit Putri Hijau terbagi menjadi 4 ruang (3 ruang rekam medis aktif dan1ruang rekam medis in aktif) dengan masingmasing luas ruangan yaitu $25 \mathrm{~m}^{2}$. Untuk penambahan 2 rak penyimpanan rekam medis aktif maka tidak memerlukan penambahan luas ruangan dikarenakan luas ruangan rekam medis aktif yang tersedia yaitu $75 \mathrm{~m}^{2}$, sedangkan kebutuhan ruangan untuk menyimpan 17 rak penyimpanan aktif hanya memerlukan luas ruangan sebanyak $42 \mathrm{~m}^{2}$.

\section{REFERENCES}

Departemen Kesehatan RI. 1997. Pedoman Pengelolaan Rekam Medis Rumah Sakit Di Indonesia. Jakarta: Direktorat Jendral Pelayanan Medik Departemen Kesehatan Republik Indonesia.

Depkes RI. 2006. Pedoman Penyelenggaraan Dan Prosedur Rekam Medis Rumah Sakit. Jakarta : Direktorat Jendral Bina Pelayanan Medik.

Huffman, E.K. 1994. Health Information Management. Illinois : Phisician Record Company.

Lubis, S. P. S., \& Handayani, J. (2018). Tinjauan Kebutuhan Rak Penyimpanan Berkas Rekam Medis Untuk 5 Tahun Kedepan Di Rumah Sakit.3(1), 404-408.

Mentri Kesehatan RI. 2008. PeraturanMenteri Kesehatan Republik Indonesia No. 269/MENKES/PER/III/2008 Tentang Rekam Medis. Jakarta : Menteri Kesehatan Republik Indonesia.

Nothoadmojo, Soekidjo. 2012. Metode Penelitian Kesehatan. Yogyakarta : Rineka Cipta. 
Pramudhita, Putri, dkk. 2014. Analisis Tata Ruang Tempat Penyimpanan Dokumen Rekam Medis Pasien Di Tinjau Dari Aspek Antropometri Petugas Rekam Medis. Jurnal Managemen Informasi KesehatanIndonesia, ISSN : 2337-585X, Vol.3, No.1.

Rustianto, Ery Dan Warih Ambar Rahayu. 2011. Manajemen Filing Dokumen Rekam Medis Dan Informasi Kesehatan. Yogyakarta : Politeknik Kesehatan Permata Indonesia.

Suprapto, haddy. 2017. Metodologi Penelitian Untuk Karya Ilmiah. Yogyakarta : Gosyen Publishing.

Undang-Undang Republik Indonesia No.29 Tahun 2004 Tentang Praktik Kedokteran. 6 Oktober 2004 Lembaran Negara republik Indonesia Tahun 2004 No.116. Jakarta.

Undang-Undang Republik Indonesia No.44 Tahun 2009 Tentang Rumah Sakit. Jakarta : Biro Hukum Departemen Kesehatan Republik Indonesia.

\section{BIOGRAPHIES OF AUTHORS}

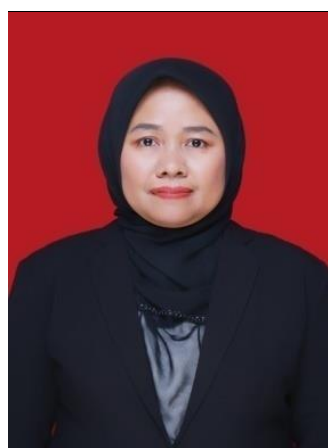

Welly Satria Dewi, Gelar Sarjana diperoleh dari STIKes Sumatera Utara, Jurusan Ilmu Kesehatan Masyarakat pada tahun 2008, dan di Politeknik Piksi Ganesha Bandung pada program D IV Informatika Rekam Medis pada tahun 2013. Magister Kesehatan Masyarakat diperoleh dari Universitas Sari Mutiara Indonesia pada tahun 2019. Saat ini aktif sebagai pengajar di Program Studi D-III Perekam Medis dan Infokes Universitas Imelda Medan. 